\title{
Production and physicochemical properties of carboxymethyl cellulose films enriched with spent coffee grounds polysaccharides
}

\author{
Lina F. Ballesteros ${ }^{a}$, Miguel A. Cerqueira ${ }^{\mathrm{b}}$, José A. Teixeira ${ }^{\mathrm{a}}$, Solange I. Mussatto ${ }^{\mathrm{c}, *}$ \\ ${ }^{a}$ Centre of Biological Engineering, University of Minho, Campus Gualtar, 4710-057, Braga, Portugal \\ b International Iberian Nanotechnology Laboratory,Av. Mestre José Veiga s/n, 4715-330, Braga, Portugal \\ ${ }^{c}$ Novo Nordisk Foundation Center for Biosustainability, Technical University of Denmark, Kemitorvet, Building 220, 2800, Kongens Lyngby, Denmark
}

\section{A R T I C L E I N F O}

\section{Article history:}

Received 5 July 2017

Received in revised form 8 August 2017

Accepted 9 August 2017

Available online 12 August 2017

\section{Keywords:}

Spent coffee grounds

Polysaccharides

Edible films

\begin{abstract}
A B S T R A C T
Extracts rich in polysaccharides were obtained by alkali pretreatment (PA) or autohydrolysis (PB) of spent coffee grounds, and incorporated into a carboxymethyl cellulose (CMC)-based film aiming at the development of bio-based films with new functionalities. Different concentrations of PA or PB (up to $0.20 \% \mathrm{w} / \mathrm{v}$ ) were added to the CMC-based film and the physicochemical properties of the final films were determined. Scanning electron microscopy, Fourier-transform infrared spectroscopy, X-ray diffraction, thermogravimetric analysis, as well as determinations of optical and mechanical properties, moisture content, solubility in water, water vapor permeability, contact angle and sorption isotherms were performed. The addition of PA or PB resulted in important changes in the properties of the CMC-based film, mainly in color and opacity. The polysaccharides incorporation significantly improved the light barrier of the film and provided an enhancement or at least a preservation in the physicochemical properties.
\end{abstract}

(c) 2017 Elsevier B.V. All rights reserved.

\section{Introduction}

Nowadays, there is a great interest in the textile, pharmaceutical, cosmetic and food industries to find new materials from renewable resources able to replace the petroleum-based materials in order to produce new biodegradable packaging with properties similar to the synthetic ones but with reduced environmental impact and with low production costs [1]. Bio-based films or coatings are considered promising alternatives to replace the synthetic materials used in the food packaging industry, for example. The use of natural polymers such as polysaccharides, proteins and lipids into edible coatings and films have been studied as an alternative to improve food preservation, since they act as semi-permeable barriers to gases and water vapor [2] and thus can be used as a packaging material. These packages can be used as potential carriers of additives and bioactive compounds to maintain or even improve the nourishing and sensory features of products [3]. Additionally, edible films and coatings are expected to present good mechanical properties, provide a better visual aspect, reduce microbiologi-

\footnotetext{
* Corresponding author.

E-mail addresses: smussatto@biosustain.dtu.dk, solangemussatto@hotmail.com (S.I. Mussatto).
}

cal contamination, and counteract the loss flavors among others, improving the food quality and safety and simultaneously increasing their shelf life.

The origin of the biodegradable compounds and their chemical structure, which can be modified depending on the techniques employed during the extraction process, play an important role in the production and features of films and coatings. The type of molecular linkage and shape, the molecular weight, and the degree of polymerization of the compounds can widely influence the physicochemical properties of the final matrix and affect the synergistic interactions among materials [2]. Currently, polysaccharide-based films have attracted great attention not only due to the capacity to blend between them, but also with others compounds, and their improved properties.

The extraction of functional materials from agricultural residues has been extensively studied in the last years. In the present study, attention was given to spent coffee grounds (SCG), the main solid coffee waste obtained during the process for preparation of soluble coffee [4]. In the last decade, the reuse of SCG has attracted great attention since this material is rich in polysaccharides and phenolic compounds [5-7] and presents important properties that would allow its reutilization in different industrial areas including food, pharmaceutical and cosmetic [8,9]. For example, SCG polysac- 
charides were demonstrated to have functional properties such as antioxidant and antimicrobial activities [10], immunostimulatory capacity [11] and thermostability in a large range of temperature [10]. These type of polysaccharides are mainly galactomannans, which are non-toxic and therefore has been used as stabilizers and stiffeners of emulsions in different areas including food, and arabinogalactans, which are also used in food due to their capacity to retain water, forming low viscosity emulsions.

On the other hand, carboxymethyl cellulose (CMC), which is one of the most important cellulose derivatives, presents a hydrophobic polysaccharide backbone and many hydrophilic carboxyl groups. It is usually used as thickener or viscosity modifier in different fields since is generally recognized as safe (GRAS) and approved for use in foods. CMC also presents excellent film-forming properties due to its biocompatibility with substances such as water-soluble polysaccharides, proteins, surfactants and plasticizers [12]. The latter are particularly used to facilitate processing and improve the flexibility of films, being glycerol and sorbitol the most utilized plasticizers due to their stability, edibility [13] and hydrophilic nature, being thus compatible with hydrophilic matrices.

Some studies report the incorporation of polysaccharides extracted from natural sources into edible films or coatings for food applications $[1,3,12]$, being such polysaccharide-based films able to maintain the quality and safety of different food products. However, to the best of our knowledge, there is not any study on the utilization of polysaccharide rich extracts obtained from SCG blended with CMC to produce films. Therefore, the main objective of this study was to develop CMC-based films enriched with SCG extracts containing polysaccharides, which were obtained by two different methods (alkali pretreatment and autohydrolysis) and evaluate the physicochemical properties of the produced films.

\section{Materials and methods}

\subsection{Materials for films production}

Polysaccharide rich extracts were obtained from SCG by two different extraction methods: alkali pretreatment and autohydrolysis, and were named as PA and PB, respectively. The alkali pretreatment was performed using $4 \mathrm{M}$ sodium hydroxide and $0.02 \mathrm{M}$ sodium borohydride, at $25^{\circ} \mathrm{C}$, overnight [10]; while the autohydrolysis was performed using $15 \mathrm{~mL}$ water/g SCG, during $10 \mathrm{~min}$ at $160^{\circ} \mathrm{C}$ [14]. The composition of sugars and phenolic compounds in the polysaccharide extracts were determined by HPLC and by the FolinCiocalteu method, respectively [10,14].

Carboxymethylcellulose- CMC (Blanose, 7M65) was obtained from Ashland Inc (Düsseldorf, Germany), analytical reagent grade glycerol 99.5\% was purchased from Himedia (Mumbai, India) and ultrapure water from a Milli-Q System (Millipore Inc., USA) was used.

\subsection{Films production}

CMC solutions were prepared by dissolving CMC in ultrapure water at $70^{\circ} \mathrm{C}$, during $4 \mathrm{~h}$ at constant agitation (300 rpm) using a magnetic stirrer. Subsequently, glycerol was added and left under agitation one more hour. On the other hand, different concentrations $(0.05 \%, 0.10 \%$ and $0.20 \% \mathrm{w} / \mathrm{v})$ of $\mathrm{PA}$ and $\mathrm{PB}$ were dissolved in ultrapure water and kept at $20^{\circ} \mathrm{C}$ during $3 \mathrm{~h}$ under magnetic agitation. Each one of the PA and PB solutions was slowly added to $\mathrm{CMC}$-glycerol solution and maintained for $30 \mathrm{~min}$ at $70^{\circ} \mathrm{C}$. The components of the films were prepared and mixed taking into account the desired concentrations in the end, which was $1.50 \%$ of CMC and $0.50 \%$ of glycerol with increasing concentrations of $\mathrm{PA}$ or $\mathrm{PB}(0.05 \%$, $0.10 \%$ and $0.20 \% \mathrm{w} / \mathrm{v}$ ). The concentrations of PA and PB were cho- sen based on preliminary experiments (data not shown) where six different concentrations were evaluated. Films were produced by casting a constant amount $(27 \mathrm{~mL})$ of film-forming solution into $90 \mathrm{~mm}$ diameter Petri dishes, dried at $33^{\circ} \mathrm{C}$ for $48 \mathrm{~h}$. Films were stored at $20^{\circ} \mathrm{C}$ and $53 \%$ relative humidity ( $\mathrm{RH}$ ) in a desiccator containing a saturated solution of $\mathrm{Mg}\left(\mathrm{NO}_{3}\right)_{2}$ until further analysis.

\subsection{Characterization of the films properties}

\subsubsection{Film thickness}

Film thickness was measured using a digital micrometer (No. 293-561, Mitutoyo, Japan). Ten measurements were made to each sample, in different points of the film.

\subsubsection{Morphology}

Images of PA and PB as well as of the produced films were obtained by scanning electron microscopy (SEM) using an Ultrahigh resolution Field Emission Gun Scanning Electron Microscope (Nova 200 Nano SEM, FEI Company, Eindhoven, Netherlands). The films were examined on the surface and transversely. For the crosssection analyses, they were fractured using liquid nitrogen and after that, all the samples were covered with a very thin film $(10 \mathrm{~nm})$ of Au-Pd (80-20 wt.\%). Images were obtained by applying an acceleration voltage of $10 \mathrm{kV}$, at 5000 -fold magnification.

\subsubsection{Crystallinity and chemical bonding of constituents}

Crystalline phases of the films were evaluated by X-ray diffraction (XRD) using a D8 Discover diffractometer (Bruker, corporation) with $\mathrm{Cu}$ tube $(\lambda=1.5406 \AA)$. The radiation was generated at $25 \mathrm{~mA}$ and $35 \mathrm{kV}$. The scattering angle of $2 \theta$ from $10^{\circ}$ to $100^{\circ}$ was measured at the step size of 0.04 and $1 \mathrm{~s}$ exposure at each step.

Chemical groups and bonding arrangement of constituents present in the films were determined by Fourier transform infrared spectroscopy (FTIR) using a Perkin- Elmer 16 PC spectrometer (Boston, USA) equipped with a diamond-composite attenuated total reflectance (ATR) cell. The measurements were recorded with a wavenumber range from 4000 to $400 \mathrm{~cm}^{-1}$ and 16 scans per sample.

\subsubsection{Thermal behavior}

Thermogravimetric analyses (TGA) were conducted using an equipment TGA Q500 (TA instruments, USA). Approx. $2 \mathrm{mg}$ of the film sample were placed in an aluminum pan. The measurements were carried out between 25 and $480^{\circ} \mathrm{C}$ with an increasing rate of $10^{\circ} \mathrm{C}$ per min under nitrogen atmosphere. TA Universal Analysis software (TA instruments, universal analysis 2000, USA) was used for data analysis.

\subsubsection{Mechanical properties}

Mechanical properties including tensile strength (TS) and elongation at break (EB) of the films were determined using an Instron Universal Testing Machine (model 4500, Instron Corporation, Canton, USA), according to the ASTM D882-10 Standard method for tensile properties of thin plastic sheeting as previously described [15]. Each sample was properly cut and set to an initial grip separation at $100 \mathrm{~mm}$, and a force and deformation speed of $50 \mathrm{~mm}$ per min. TS was calculated by dividing maximum load ( $\mathrm{N}$ ) by crosssectional area of the film $\left(\mathrm{m}^{2}\right)$ and expressed in mega Pascal (MPa). EB was calculated as the ratio of the final length at the point of sample rupture to the initial length of the sample and expressed in percentage (\%). At least six replicates were performed to each film.

\subsubsection{Moisture content and water solubility}

Moisture content of the films was determined by gravimetric analysis, placing approx. $30 \mathrm{mg}$ of sample at $105^{\circ} \mathrm{C}$ during $24 \mathrm{~h}$ (until constant weight). The weight loss of the samples was 
then determined, and the moisture content was calculated and expressed as percentage.

For the determination of water solubility, films free of moisture with $2 \mathrm{~cm}$ diameter were weighed and subsequently immersed in $50 \mathrm{~mL}$ of distilled water and placed in a shaker at $120 \mathrm{rpm}$, room temperature during $24 \mathrm{~h}$. The samples were taken out and dried at $105{ }^{\circ} \mathrm{C}$ (until constant weight). Solubility was determined by the weight difference between the dry matter that was not solubilized in water and the initial weight before immersion. Three replicates were made to each film and the solubility results were expressed as percentage (\%).

\subsubsection{Water vapor permeability}

Water vapor permeability (WVP) was determined gravimetrically according to ASTM E96-95 Standard test. Briefly, the films were sealed on the top of permeation cells containing $60 \mathrm{~mL}$ of distilled water $\left(100 \% \mathrm{RH}\right.$ and $2337 \mathrm{~Pa}$ vapor pressure at $\left.20^{\circ} \mathrm{C}\right)$ and then, placed into a desiccator with silica gel $(0 \% \mathrm{RH}$ and 0 Pa water vapor pressure at $20^{\circ} \mathrm{C}$ ). The cells were weighted at $2 \mathrm{~h}$ intervals for monitoring the weight loss during $10 \mathrm{~h}$. Steady state and uniform water pressure conditions were assumed by keeping the air circulation constant outside the test cell by using a miniature fan inside the desiccator. Water vapor transmission rate (WVTR) was determined by dividing the slope of the linear regression of weight loss versus time by the film area (expressed as $\mathrm{g} / \mathrm{s} \mathrm{m}^{2}$ ). Afterwards, WVTR was multiplied by the film thickness and divided by the vapor partial pressure difference to obtain WVP (expressed as $\mathrm{g} / \mathrm{m} \mathrm{s} \mathrm{Pa}$ ). Three replicates were made to each film.

\subsubsection{Water sorption isotherms}

Water adsorption/desorption isotherms of the films were determined at $25^{\circ} \mathrm{C}$ using an AquaLab moisture 4TE analyzer (Decagon Devices, Inc., USA). Prior analysis, the films were placed into a desiccator with silica gel $\left(0 \% \mathrm{RH}\right.$ at $\left.25^{\circ} \mathrm{C}\right)$ for at least 5 days, and then weighted. Water activity $\left(a_{w}\right)$ was varied from 0.11 to 0.97 using different saturated salt solutions such as lithium chloride ( $\mathrm{LiCl})$, magnesium chloride $\left(\mathrm{MgCl}_{2}\right)$, magnesium nitrate $\left(\mathrm{Mg}\left(\mathrm{NO}_{3}\right)_{2}\right)$, sodium chloride $(\mathrm{NaCl})$, and potassium sulfate $\left(\mathrm{K}_{2} \mathrm{SO}_{4}\right)$, with $a_{w}$ of $0.11,0.33,0.53,0.75$ and 0.97 , respectively. For the measurements, the film sample was left on the top of an especial cup containing $5 \mathrm{~mL}$ of each saturated salt solution and placed into the moisture analyzer chamber. When the atmosphere within the chamber reached the equilibrium, the film was quickly removed and weighed again. Adsorption isotherms were obtained by starting the measurements from low $a_{w}$ to high $a_{w}$ values, on the inverse way for desorption isotherms. Moisture content was determined at the equilibrium as the difference between the weight before and after the samples were in the presence of the saturated salt solutions. Results were expressed as grams of water per $100 \mathrm{~g}$ of dry film at each $a_{w}\left(\mathrm{~g} \mathrm{H}_{2} \mathrm{O} / 100 \mathrm{~g}\right.$ dry film). Guggenheim, Anderson and De Boer (GAB) model was used for fitting the experimentally obtained data through Eq. (1), where $M$ is the equilibrium moisture content at a specific $a_{w}\left(\mathrm{~g} \mathrm{H}_{2} \mathrm{O} / 100 \mathrm{~g}\right.$ dry film $), M_{m}$ represents the monolayer moisture content ( $\mathrm{g} \mathrm{H}_{2} \mathrm{O} / 100 \mathrm{~g}$ dry film), $C$ is the Guggenheim constant related to thermal effect and $k$ the corrective constant related to the properties of multilayer water molecules with respect to bulk liquid.

$M=\frac{M_{m} C k a_{w}}{\left[\left(1-k a_{w}\right)\left(1-k a_{w}+C k a_{w}\right)\right]}$

The parameters of the model were estimated with the nonlinear regression procedure. The fit accuracy was evaluated by the mean of the relative percent difference between the experimental and predicted values of moisture content, being defined as the mean relative deviation modulus $(G)[16]$, and determined using Eq (2), where $n$ is the number of observations, $M_{a}$ is the experimentally determined moisture content ( $\mathrm{g} \mathrm{H}_{2} \mathrm{O} / 100 \mathrm{~g}$ dry film) and $M_{p}$ is the predicted moisture content ( $\mathrm{g} \mathrm{H}_{2} \mathrm{O} / 100 \mathrm{~g}$ dry film).

$G=\frac{100}{n} \sum_{i=1}^{n}\left(\frac{\left|M_{a i}-M_{p i}\right|}{M_{a i}}\right)$

$G$ values lower than 5 correspond to extremely good fit, between 5 and 10 show a reasonably good fit and values greater than 10 are considered a poor fit [16].

\subsubsection{Surface hydrophobicity}

Surface hydrophobicity of the films was evaluated by measuring the contact angle of a water droplet $(\theta)$ upon the film surface through an optical contact angle meter (OCA 20, Dataphysics, Germany). The measurements were made according to sessile drop method using a $500 \mu \mathrm{L}$ syringe (Hamilton, Switzerland) with needle of $0.75 \mathrm{~mm}$ diameter containing ultrapure water. The samples were put on a glass and then $2 \mu \mathrm{L}$ of ultrapure water were placed on the film surface. Measurements were made from 0 to $12 \mathrm{~min}$ and the contact angle was determined by using the measuring system OCA 15 Plus and C20 software with CCD video camera (resolution of $752 \times 582$ pixel) at $24.7^{\circ} \mathrm{C}$. Ten replicates were made to each film.

\subsubsection{Optical properties - color and opacity}

Color parameters and opacity of the films were determined with a Minolta colorimeter (CR 400, Minolta, Japan). A white standard color plate $(Y=93.9, x=0.3158, y=0.3321)$ was used for the equipment calibration and as background for the color measurements, being the $L^{*}, a^{*}, b^{*}$ values determined by reflectance. In the color system $L^{*}$ represents the luminosity (ranging from black to white). Thus, low $L^{*}$ values correspond to dark, while high $L^{*}$ values belong to light. On the other hand, $a^{*}$ and $b^{*}$ are the chromatic coordinates, where $+a^{*}$ and $-a^{*}$ are in the red and green directions, respectively, while, $+b^{*}$ is in the yellow direction, and $-b^{*}$ is in the blue direction. The $a^{*}$ and $b^{*}$ values approach zero for neutral colors and increase when the color becomes more chromatic and more saturated.

Opacity was determined according to the Hunter lab method, as the relationship between the opacity of each sample on a black standard $\left(Y_{b}\right)$ and the opacity of each sample on a white standard $\left(Y_{w}\right)$ [17]. For both, color and opacity analyses, ten measurements were made to each film. The solubility was expressed in percentage. The color and opacity of the films were simulated using an image software (Photoshop CS6).

\subsection{Statistical analysis}

Statistical analysis was carried out using GraphPad Prism (version 6.1). One-way analysis of variance (ANOVA) and Tukey's multiple comparison test were performed to determine the significant differences $(p<0.05)$ between film samples.

\section{Results and discussion}

\subsection{Characterization of the polysaccharides present in SCG extracts}

The polysaccharideís rich extracts obtained by alkali pretreatment [10] and autohydrolysis [14] of SCG were characterized in terms of percentage of total carbohydrates and content of total phenolic compounds (Table 1). As can be seen, the total content of polysaccharides was higher in PA $(39 \%, w / w)$ than in PB $(29 \%$, $\mathrm{w} / \mathrm{w}$ ). Although the sugars composition was different for PA and PB, both extracts contained galactose, arabinose, mannose and glucose, which are present in coffee forming galactomannan, arabinogalactan and cellulose structures [7,10,14]. Unlike polysaccharides, the content of total phenolic compounds and moisture were slightly 
Table 1

Chemical composition of polysaccharideís rich extracts obtained by alkali pretreatment (PA) or autohydrolysis (PB) of spent coffee grounds.

\begin{tabular}{|c|c|c|}
\hline \multirow[t]{2}{*}{ Components } & \multicolumn{2}{|l|}{ Extract $^{\mathrm{a}}$} \\
\hline & PA & $\mathrm{PB}$ \\
\hline Total polysaccharides content (g/100 g lyophilized) & $39.00 \pm 0.19$ & $29.29 \pm 3.47$ \\
\hline Arabinose $(\% \mathrm{~mol})$ & $19.93 \pm 1.74$ & $10.02 \pm 1.18$ \\
\hline Mannose (\% mol) & $4.43 \pm 0.16$ & $31.88 \pm 2.08$ \\
\hline Galactose $(\% \mathrm{~mol}) \quad$ Glucose $(\% \mathrm{~mol})$ & $60.27 \pm 0.5115 .37 \pm 0.93$ & $47.74 \pm 0.1310 .35 \pm 0.76$ \\
\hline Phenolic compounds (mg GAE/g lyophilized) & $230.14 \pm 1.43$ & $234.14 \pm 5.30$ \\
\hline Moisture & $15.50 \pm 1.50$ & $17.50 \pm 2.10$ \\
\hline
\end{tabular}

${ }^{\text {a }}$ From $[10,14]$. Results are expressed as mean \pm standard deviation; $\mathrm{n}=3$.

higher in PB than in PA, although the differences were not significant at $p<0.05$.

\subsection{Morphology}

Images obtained by scanning electron microscopy for PA and PB, as well as surface and cross sectional images of the produced films are shown in Fig. 1a and b, respectively. Both, PA and PB revealed significant morphological differences. PA presented denser morphology, composed of thin sheets that resembles to sawdust, while PB consisted of a more porous material (Fig. 1a). On the other hand, when analyzing the CMC-based films without and with incorporation of PA and PB at different concentrations (Fig. 1b), the images showed different characteristics (surface and cross-section images) for the enriched films. For films enriched with PA, there were no evidence of pores or surface features, independently of the PA concentration added (similar images for all concentrations used). Thus, CMC-based films without or with PA addition exhibited a uniform and compact structure, suggesting a good incorporation of PA into the matrix film. On the contrary, when PB was added into the CMCbased films, a clear increase of the surface defects was observed as the concentration was raised. This behavior was corroborated during the film-forming process, being PB more difficult to dissolve in water than PA. This fact may be related to the molecular weight and possible structural differences between both samples [18]. Additionally, the morphological differences on the surface of the films containing PA or PB may be due to the processes used to obtain these extracts and the different stages employed in each method, since PA was dialyzed though a membrane of $8000 \mathrm{Da}$, while PB was not submitted to this stage, which could have extended its polymerization degree.

\subsection{Crystallinity and chemical bonding of constituents}

Fig. 2a and b shows the X-ray diffraction (XRD) and Fourier transform infrared spectroscopy (FTIR) spectra of the samples, respectively. Results show that the incorporation of low concentrations of PA and PB $(0.05-0.20 \%, w / v)$ lead to slight changes in the structural characteristics of the films.

The XRD pattern of the films, as well as for PA, PB and CMC samples are shown in Fig. 2a. As can be seen, after the film formation, CMC suffers a structural change, evidenced by the disappearance of a very weak broad peak located around $2 \theta=36^{\circ}$, which distinguishes the pure CMC structure [19]. The acquired structure was maintained even when PA and PB were added to the CMCbased film. All the films revealed a semi-crystalline diffraction peak around $2 \theta=20.6^{\circ}$, which is characteristic of cellulose. The full width at half maximum (FWHM) of this peak was calculated in order to analyze possible differences between the samples. The results shown that the crystallinity of pure CMC decreased when CMC was used to film-forming (i.e. higher values of FWHM), since polysaccharides naturally interact with water generating structural transitions (amorphous or crystalline), which plays an important role on the mobility of the molecules and thus on the functional properties of the films [20]. Although the differences among the films with respect to FWHM were very small, it can be seen that the incorporation of $\mathrm{PA}$ or $\mathrm{PB}$ into the CMC-based film increased the crystallinity of the film, suggesting an influence of $\mathrm{PA}$ or $\mathrm{PB}$ in the film matrix.

FTIR spectra (Fig. 2b) revealed the same structure and chemical bonds for the CMC-based films without and with incorporation of PA or PB, evidencing that the incorporation of PA and PB did not change the chemical structure of the CMC-based film. The same transmission bands of pure CMC were observed in all the films. However, the intensity of the peaks was increased after formation of the film, which is explained by the physical blends and chemical interactions of the final film matrix with the other compounds. The transmission band between 3000 and $3600 \mathrm{~cm}^{-1}$ relates to the hydrogen bonding $\mathrm{OH}$ stretching vibration, being a characteristic of moist materials, which was intensified by the presence of glycerol in films [21]. The peak at $2920 \mathrm{~cm}^{-1}$ corresponds to the $\mathrm{C}-\mathrm{H}$ stretch, and the band at $1590 \mathrm{~cm}^{-1}$ confirms the presence of $\mathrm{COO}^{-}$ being assigned to stretching of the carboxyl group [19]. The bands at $1410 \mathrm{~cm}^{-1}$ and $1320 \mathrm{~cm}^{-1}$ are related to $\mathrm{OH}$ stretching in plane and $\mathrm{C}-\mathrm{H}$ stretching in symmetric of $\mathrm{CMC}$ [12]. The peaks depicted at $1110 \mathrm{~cm}^{-1}$ and $1040 \mathrm{~cm}^{-1}$ are characteristic of the $\mathrm{C}-\mathrm{O}$ stretching on polysaccharide skeleton. Additionally, CMC-based films containing or not PA and PB showed soft bands at $948 \mathrm{~cm}^{-1}$ and $884 \mathrm{~cm}^{-1}$, which did not appear in pure CMC and are justified by the presence of glycerol [22]. These peaks were also observed in films where glycerol was used as plasticizer corresponding to asymmetric and symmetric stretching vibrations of the alcoxyl group $(C-O-C)$ [21]

\subsection{Thermal behavior}

Thermogravimetric analyses (TGA) (Fig. 3) were carried out in order to evaluate the stability of CMC-based films enriched with $\mathrm{PA}$ or $\mathrm{PB}$. When the films were exposed to heating until $480^{\circ} \mathrm{C}$, three weight loss stages were identified. The first stage (60-130 ${ }^{\circ} \mathrm{C}$ ) was associated to water evaporation and chemisorbed water through hydrogen bonds. It can be seen that the CMC-based films with $0.10 \%$ and $0.20 \%(\mathrm{w} / \mathrm{v})$ of PA were stable up to about $95^{\circ} \mathrm{C}$, while all the others showed stability up to $45-60^{\circ} \mathrm{C}$ only, suggesting that the water loss occurred more slowly in the films containing PA at $0.10 \%$ and $0.20 \%(\mathrm{w} / \mathrm{v})$. This behavior was maintained until the beginning of the second stage, where the maximum rate of mass loss (40-45\%) occurred for all the films, taking place at approx. $270^{\circ} \mathrm{C}$. The weight loss in the last stage, around $300-350^{\circ} \mathrm{C}$ was attributed to degradation of the polysaccharides.

\subsection{Mechanical properties}

Table 2 shows the elongation at break (EB) and tensile strength (TS) values obtained for the films. CMC-based film without PA and $\mathrm{PB}$ presented similar EB values to those reported in another study using CMC at $1.50 \%(\mathrm{w} / \mathrm{v})$ (same concentration used in the 
a)

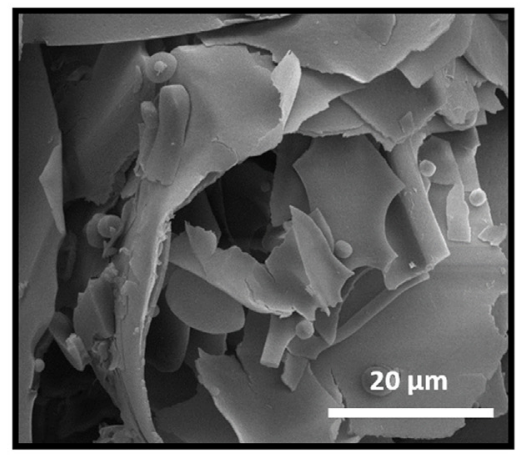

PA

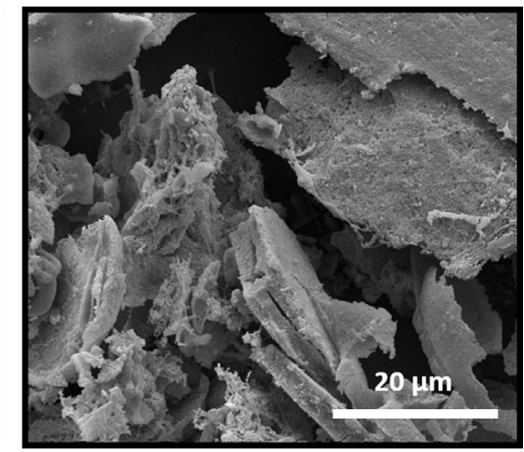

PB

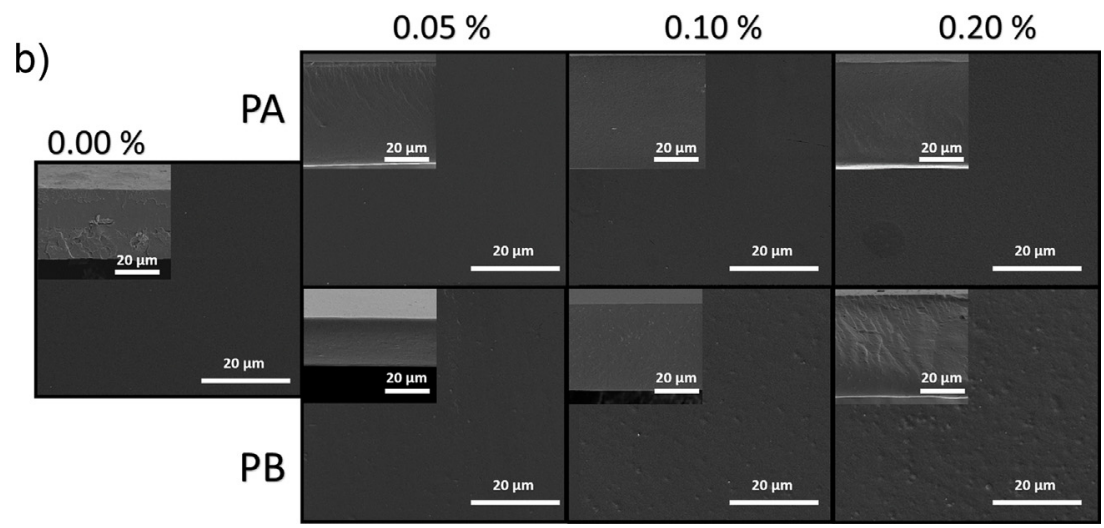

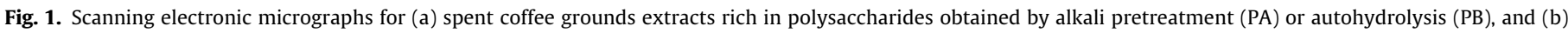
surface and cross-sectional images of CMC-based films without and with PA or PB incorporation at different concentrations. Magnification, 5000-fold.

Table 2

Color parameters, opacity, elongation at break (EB) and tensile strength (TS) values of the CMC-based films without and with different PA or PB concentrations.

\begin{tabular}{|c|c|c|c|c|c|c|}
\hline Extract concentration $(\%, \mathrm{w} / \mathrm{v})$ & $L^{*}$ & $a^{*}$ & $b^{*}$ & Opacity (\%) & $\mathrm{EB} \quad(\%)$ & (MPa) \\
\hline $0.00(\mathrm{CMC})$ & $96.63 \pm 0.44^{\mathrm{a}}$ & $0.14 \pm 0.05^{\mathrm{a}}$ & $2.74 \pm 0.42^{\mathrm{a}}$ & $9.39 \pm 0.76^{\mathrm{a}}$ & $10.54 \pm 0.17^{\mathrm{a}}$ & $14.18 \pm 3.71^{\mathrm{a}}$ \\
\hline PA 0.05 & $81.01 \pm 1.17^{b}$ & $4.74 \pm 0.30^{\mathrm{b}}$ & $27.08 \pm 0.81^{b}$ & $12.38 \pm 1.40^{\mathrm{ad}}$ & $8.95 \pm 0.65^{\mathrm{ab}}$ & $22.86 \pm 2.24^{\mathrm{bc}}$ \\
\hline PA 0.10 & $63.52 \pm 0.84^{c}$ & $13.95 \pm 0.39^{c}$ & $41.30 \pm 0.39^{c}$ & $17.99 \pm 0.74^{\text {be }}$ & $7.96 \pm 1.38^{\mathrm{ab}}$ & $19.59 \pm 4.17^{\mathrm{abd}}$ \\
\hline PA 0.20 & $51.27 \pm 1.96^{\mathrm{d}}$ & $20.10 \pm 0.93^{d}$ & $39.19 \pm 0.75^{d}$ & $26.66 \pm 3.82^{c}$ & $6.56 \pm 0.86^{\mathrm{bc}}$ & $22.33 \pm 2.35^{\mathrm{bc}}$ \\
\hline PB 0.05 & $71.91 \pm 0.70^{\mathrm{e}}$ & $8.38 \pm 0.27^{e}$ & $31.69 \pm 0.60^{\mathrm{e}}$ & $15.47 \pm 1.48^{\mathrm{bd}}$ & $4.50 \pm 1.99^{c}$ & $16.43 \pm 0.14^{\mathrm{ab}}$ \\
\hline PB 0.10 & $55.01 \pm 2.21^{\mathrm{f}}$ & $15.81 \pm 0.77^{f}$ & $36.08 \pm 0.80^{f}$ & $21.17 \pm 2.22^{\mathrm{e}}$ & $6.84 \pm 0.43^{\mathrm{bc}}$ & $26.04 \pm 1.29^{c}$ \\
\hline PB 0.20 & $33.86 \pm 2.55^{\mathrm{g}}$ & $17.92 \pm 1.69^{g}$ & $20.54 \pm 2.69^{g}$ & $53.00 \pm 8.78^{\mathrm{f}}$ & $8.22 \pm 1.02^{\mathrm{ab}}$ & $23.35 \pm 0.89^{\mathrm{cd}}$ \\
\hline
\end{tabular}

Different letters in the same column correspond to samples statistically different at $95 \%$ confidence level.

PA and PB: extracts rich in polysaccharides obtained by alkali pretreatment or autohydrolysis of spent coffee grounds, respectively.

present study) [23]. The addition of PA and PB lead to a decrease of the EB values when compared to the non-enriched CMC-based film, showing significant differences $(p<0.05)$ for films with the highest concentration of PA $(0.20 \% \mathrm{w} / \mathrm{v})$ and the lowest concentrations of $\mathrm{PB}(<0.10 \% \mathrm{w} / \mathrm{v})$. As can be seen, the behavior of the films containing PA and PB was completely opposite with relation to the concentration added. This fact suggests that the interaction between film matrix with PB lead to films stiffer and more compact when using the lowest concentration, becoming more extensible as the concentration increased. In contrast, the presence of PA in the film matrix increased the chains mobility and flexibility at lower concentrations, and its stiffness when the PA was used at higher concentrations. These results are directly related to the water solubility data, where the same behavior was observed.

On the other hand, the TS values indicated significant changes $(p<0.05)$ when PA or PB were added to the films, with exception to films containing $0.05 \%(\mathrm{w} / \mathrm{v})$ of $\mathrm{PB}$ and $0.10 \%(\mathrm{w} / \mathrm{v})$ of PA. TS values of CMC-based films containing PA did not suffer significant modifications when the concentration of PA was changed. How- ever, for films containing $\mathrm{PB}$, the TS values raised when the $\mathrm{PB}$ concentration was increased, obtained thus, higher TS values when using $0.10 \%$ and $0.20 \%(\mathrm{w} / \mathrm{v})$. These results are in agreement with other studies (films with phenolic compounds, gelatin or proteins) $[24,25]$, where it was demonstrated that the interactions between the matrix components are determined by the chain length of the materials added.

\subsection{Moisture content}

Moisture content provides information about the water affinity of the films and gives indication on how PA and PB could influence their properties. As can be seen in Table 3, all the films presented very close values of moisture content. Nevertheless, films containing PB at $0.20 \%(\mathrm{w} / \mathrm{v})$ showed a lower moisture $(p<0.05)$ compared to the non-enriched CMC-based film, while for all other films no differences were observed $(p>0.05)$. For films containing PA, a difference was noticed when using $0.10 \%$ and $0.20 \%(w / v)$, presenting the former a higher moisture content, while for PB a difference 

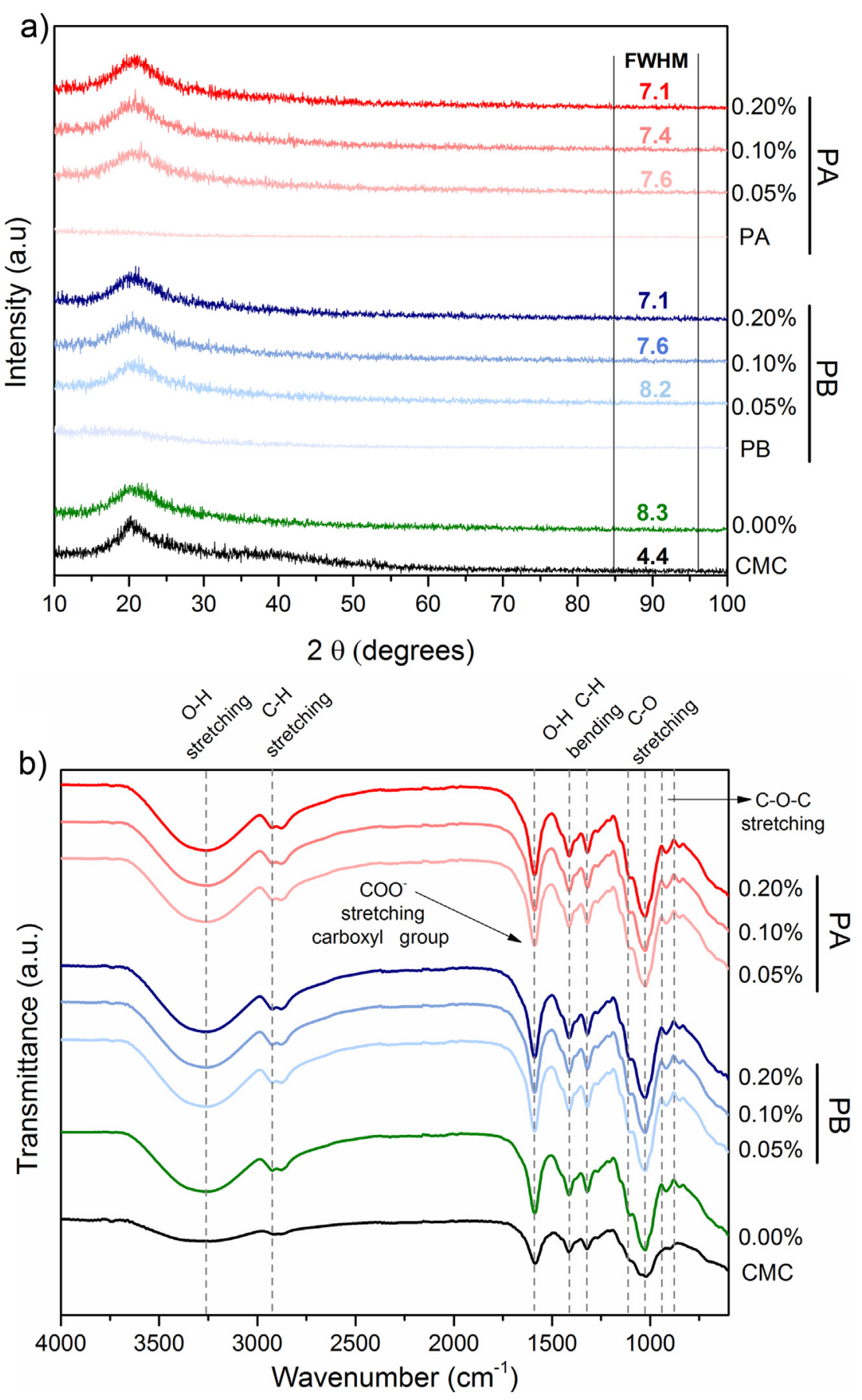

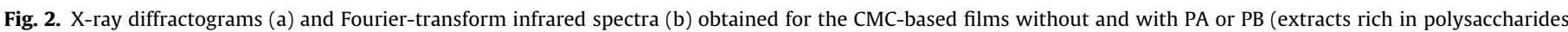
obtained by alkali pretreatment or autohydrolysis of spent coffee grounds, respectively) incorporation at different concentrations.

Table 3

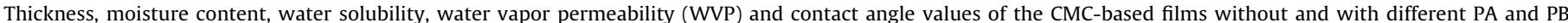
concentrations.

\begin{tabular}{|c|c|c|c|c|c|}
\hline Extract concentration $(\%, \mathrm{w} / \mathrm{v})$ & Thickness(mm) & Moisture (\%) & Water solubility(\%) & $\mathrm{WVP} \times 10^{-10}(\mathrm{~g} / \mathrm{m} \mathrm{s} \mathrm{Pa})$ & Contact angle ${ }^{a}\left({ }^{\circ}\right)$ \\
\hline 0.00 (CMC) & $0.070 \pm 0.006^{\mathrm{a}}$ & $22.71 \pm 0.87^{\mathrm{ab}}$ & $75.08 \pm 3.37^{\mathrm{a}}$ & $3.36 \pm 0.19^{a}$ & $54.80 \pm 6.29^{a}$ \\
\hline PA 0.05 & $0.068 \pm 0.005^{\mathrm{a}}$ & $23.36 \pm 1.36^{\mathrm{ab}}$ & $59.47 \pm 0.90^{\mathrm{b}}$ & $3.56 \pm 0.65^{a}$ & $104.96 \pm 2.05^{\mathrm{b}}$ \\
\hline PA 0.10 & $0.078 \pm 0.004^{\mathrm{b}}$ & $25.45 \pm 1.97^{\mathrm{a}}$ & $54.72 \pm 1.17^{\mathrm{bc}}$ & $3.66 \pm 0.33^{\mathrm{a}}$ & $108.54 \pm 2.18^{\mathrm{bc}}$ \\
\hline PA 0.20 & $0.075 \pm 0.006^{\mathrm{bc}}$ & $20.97 \pm 0.82^{\mathrm{bc}}$ & $53.10 \pm 0.18^{\mathrm{cd}}$ & $3.64 \pm 0.10^{\mathrm{a}}$ & $111.48 \pm 3.38^{c}$ \\
\hline PB 0.05 & $0.068 \pm 0.004^{\mathrm{a}}$ & $23.55 \pm 0.67^{\mathrm{ab}}$ & $49.94 \pm 1.34^{c}$ & $2.99 \pm 0.32^{\mathrm{a}}$ & $103.30 \pm 4.86^{\mathrm{b}}$ \\
\hline PB 0.10 & $0.070 \pm 0.006^{\mathrm{a}}$ & $21.63 \pm 0.32^{\mathrm{bc}}$ & $50.52 \pm 1.53^{c}$ & $3.23 \pm 0.45^{\mathrm{a}}$ & $107.34 \pm 4.12^{\mathrm{bc}}$ \\
\hline PB 0.20 & $0.071 \pm 0.008^{\mathrm{ac}}$ & $19.05 \pm 0.14^{\mathrm{c}}$ & $58.59 \pm 3.51^{\text {bd }}$ & $3.46 \pm 0.46^{\mathrm{a}}$ & $107.40 \pm 3.21^{\mathrm{bc}}$ \\
\hline
\end{tabular}

Different letters in the same column correspond to samples statistically different at 95\% confidence level.

PA and PB: extracts rich in polysaccharides obtained by alkali pretreatment or autohydrolysis of spent coffee grounds, respectively.

a Measurement at $0 \mathrm{~min}$. 


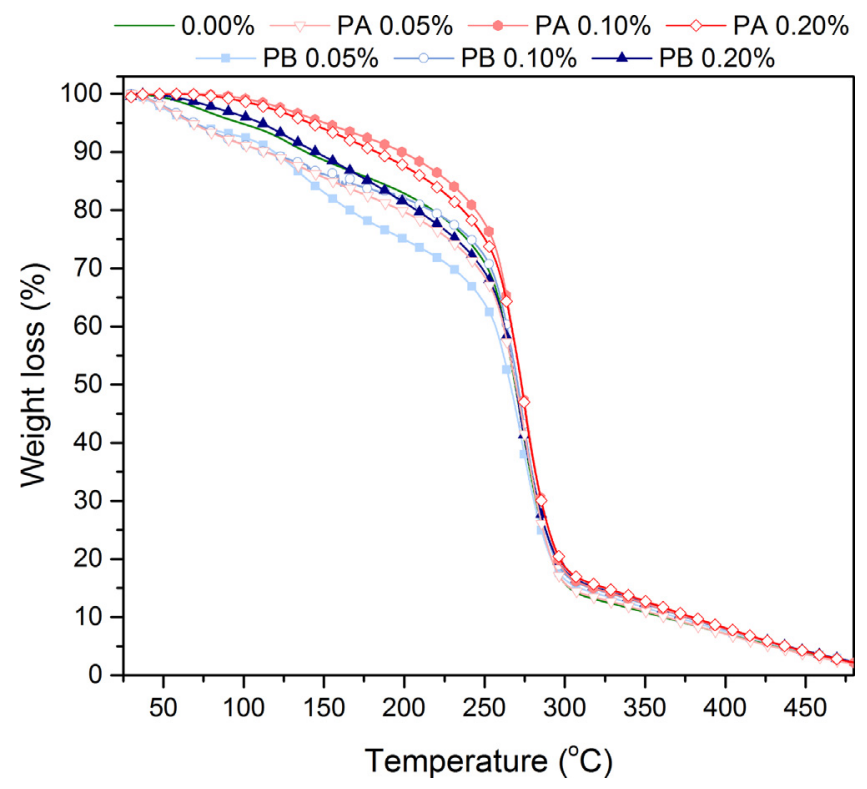

Fig. 3. Thermogravimetric curves for the CMC-based films.

was noticed when using $0.05 \%$ and $0.20 \%(\mathrm{w} / \mathrm{v})$, presenting also the former a higher moisture content. These results reveal that the incorporation of PA or PB can influence the moisture content of the film, but only using $\mathrm{PB}$ at the highest concentration a significant difference could be observed. Some authors reported that the addition of galactomannans into the film matrix could increase the water-binding capacity, but a decrease was also observed when high amounts of galactomannan were added [2,26], which is in agreement with the results observed in the present study. Finally, no significant differences between the samples were found when the lowest and the highest concentrations of PA and PB were evaluated; only for $\mathrm{PB}$ concentration of $0.10 \%$ it was observed a small decrease in the moisture content when compared with PA $0.10 \%$.

\subsection{Water solubility}

Table 3 shows the water solubility values obtained for all the films. Results revealed that the films with the addition of PA or PB presented lower $(p<0.05)$ solubility values than the nonenriched CMC-based film, showing that the incorporation of PA or PB decreased the solubility of the CMC-based film, independently of the concentration or the type of sample (PA or PB) used. Such behavior was visually corroborated after the test, since the films containing PA or PB preserved the integrity, while the non-enriched film only presented some fragments in the water. On the other hand, the films with incorporation of PA or PB had an opposite behavior, revealing a significant reduction of the solubility values with the increase of PA concentrations, whereas a significant increase was observed for higher concentrations of PB. These differences can be explained by the fact that PA showed to be better incorporated into the film matrix than PB, as demonstrated by SEM images (Fig. 1).

When comparing the water solubility for the films containing PA or PB at the same concentration, a significant difference $(p<0.05)$ was only observed for the lowest concentration $(0.05 \%$ $w / v)$, being obtained a lower value for the films containing PB. These results suggest that the differences between the molecular structures of the matrix, including the presence of semi-crystalline fraction (changes shown in the XRD section) could determine the solubility of the edible films in water.

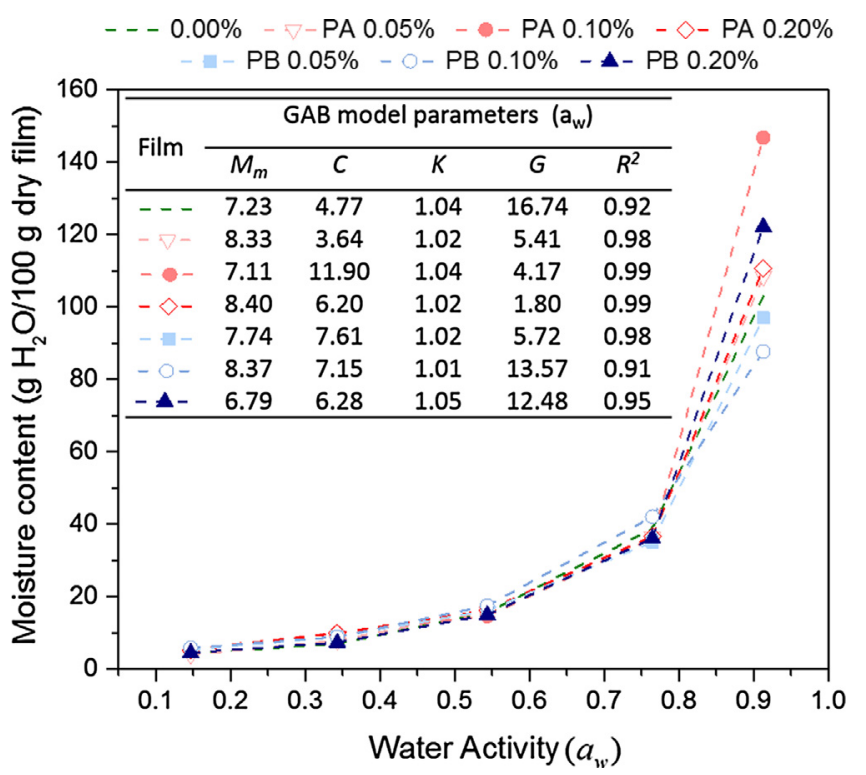

Fig. 4. Water adsorption isotherms of the CMC-based films without and with the addition of $\mathrm{PA}$ or $\mathrm{PB}$ (extracts rich in polysaccharides obtained by alkali pretreatment or autohydrolysis of spent coffee grounds, respectively) at different concentrations (measurements were performed at $25^{\circ} \mathrm{C}$ ). $M_{m}$ represents the monolayer moisture content ( $\mathrm{g} \mathrm{H}_{2} \mathrm{O} / 100 \mathrm{~g}$ dry film), $C$ is the Guggenheim constant related to thermal effect and $k$ the constant related to the properties of multilayer water molecules with respect to bulk liquid, $G$ is the mean relative deviation modulus and $R^{2}$ the coefficient of regression.

\subsection{Water vapor permeability}

Water vapor permeability (WVP) is the most widely studied property of films since it allows understanding the influence of the components present in the final matrix on features such as solubility, sorption and diffusion of water molecules. In the present study, similar WVP values were observed for all the films, showing that in the range of concentrations used for $\mathrm{PA}$ and $\mathrm{PB}$, the transport properties of CMC-based films are not changed (Table 3). The value obtained for CMC-based film $\left(3.36 \times 10^{-10} \mathrm{~g} / \mathrm{m} \mathrm{s} \mathrm{Pa}\right)$ was higher than the value found by Bifani et al. [27] $\left(7.14 \times 10^{-11} \mathrm{~g} / \mathrm{m} \mathrm{s} \mathrm{Pa}\right)$ when using CMC at $2.00 \%(\mathrm{w} / \mathrm{v})$ and glycerol and sunflower oil as plasticizers $(0.50 \%$ and $0.40 \%, \mathrm{v} / \mathrm{w}$, respectively). However, it was lower than the WVP value $\left(1.62 \times 10^{-8} \mathrm{~g} / \mathrm{m} \mathrm{sPa}\right)$ achieved using CMC at $1.50 \%(w / v)$ and glycerol $0.90 \%(w / v)$ [23]. Such difference may be due to the type and amount of plasticizer used, the presence of sunflower oil, the CMC concentration and the process used to produce the film.

\subsection{Water sorption isotherms}

Water sorption is closely related to the matrix microstructure of films and depends of the environmental relative humidity. Fig. 4 shows the adsorption isotherm profile of the studied films, presenting the variation of the moisture content with respect to the water activity $\left(a_{w}\right)$. Some authors have mentioned that the moisture sorption isotherms represent the combined hygroscopic properties of the individual components in the films [28]. In this work, all the films presented similar behavior when exposed to different relative humidity, with exception of CMC-based film with addition of PA at $0.10 \%(w / v)$, which showed a rise over the others, suggesting a higher hygroscopicity. This greater water association was confirmed by the $C$ value obtained, which was higher for these films. As can be seen, the equilibrium moisture content $\left(\mathrm{g} \mathrm{H}_{2} \mathrm{O} / 100 \mathrm{~g}\right.$ dry film) increased almost linearly until an $a_{w}$ range of $0.70-0.80$, and after, it increased exponentially. This type of nonlinear sorp- 


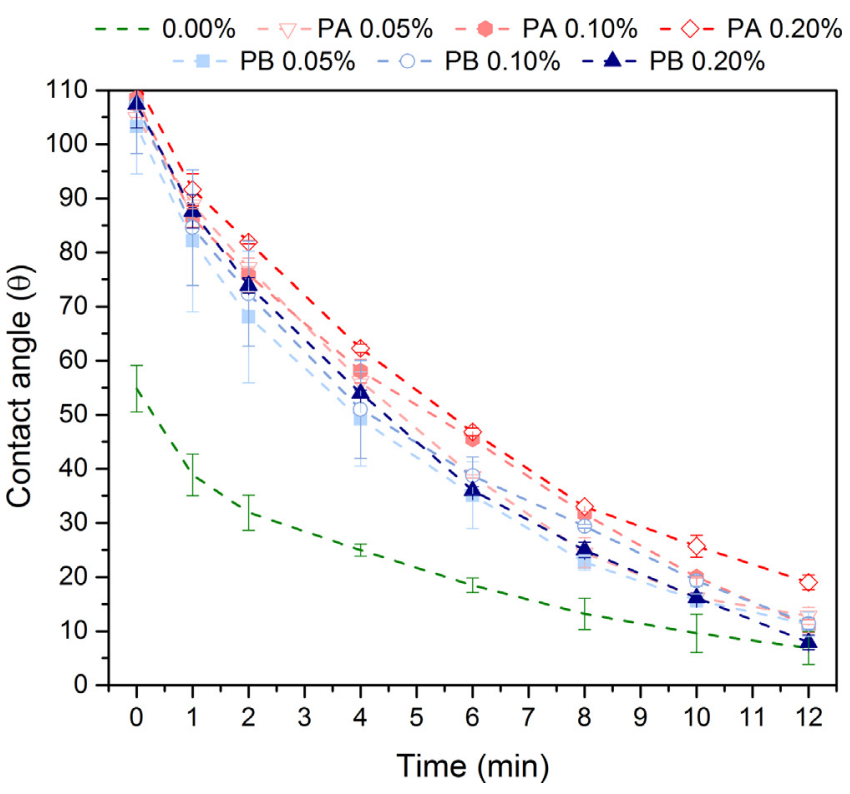

Fig. 5. Changes of contact angle measurement for CMC-based films without and with the incorporation of PA or PB (extracts rich in polysaccharides obtained by alkali pretreatment or autohydrolysis of spent coffee grounds, respectively) at different concentrations as a function of time after the drop deposition.

tion profile is typical of hydrophilic films and has been reported to others CMC-based films [29]. The general curve experimentally obtained for all the films was fitted to the GAB moisture sorption model, which evaluates $a_{w}$ ranges between 0.1 and 0.9 being widely used in food. The parameters were determined (Fig. 4) and showed $G$ values lower than 5 for PA at $0.20 \%$ and $0.10 \%(w / v)$, indicating an extremely good fit. The films containing $0.05 \%(\mathrm{w} / \mathrm{v})$ of PA or PB corresponded to a reasonably good fit ( $G$ between 5 and 10 ), while CMC-based film (control), and the films with $0.10 \%$ and $0.20 \%(\mathrm{w} / \mathrm{v})$ of PB showed values greater than 10 , corresponding to a poor fit. On the other hand, $M_{\mathrm{m}}$ values were between 6.79 and $8.40\left(\mathrm{~g} \mathrm{H}_{2} \mathrm{O} / 100 \mathrm{~g}\right.$ dry film), indicating the number of active sites available to water adsorption [30], which is strongly related to the presence of glycerol. The lower $M_{m}$ value was obtained for the film with $0.20 \%$ of PB that is in agreement with the moisture content results, which revealed this film as one with the lowest moisture content. The desorption isotherms showed a similar profile to the adsorption isotherms, indicating absence of hysteresis (results not shown).

\subsection{Surface hydrophobicity}

Surface hydrophobicity was evaluated by measuring the water contact angle on the surface of the films. Instantaneous contact angle measurements $(0 \mathrm{~s})$ revealed an increase in the hydrophobic behavior of the film surface after incorporation of PA or PB (Table 3 ). CMC-based film (non-enriched) showed a $\theta=54.80^{\circ}$. Addition of PA or $\mathrm{PB}$ modified this value to values in the range between $103^{\circ}$ and $111^{\circ} . \theta$ values of films containing PA or PB were not statistically different $(p>0.05)$ with exception to films with PA, where the contact angle value increased from $104.96^{\circ}$ to 111.48 when the concentration was raised from $0.05 \%$ to $0.20 \%$. The behavior of the water drop on the upper surface of the films was also evaluated as a function of time (Fig. 5). The results revealed that the contact angle decreased through time for all the films, but the statistic difference $(p<0.05)$ between the CMC-based film and those elaborated with PA or PB was maintained, confirming the hydrophobic behavior of the films containing PA and PB during the initial 5 min. However, at $12 \mathrm{~min}$ the film with the highest contact angle $\left(19^{\circ}\right)$ was that containing PA $0.20 \%(\mathrm{w} / \mathrm{v})$, the value being statistically different of the others

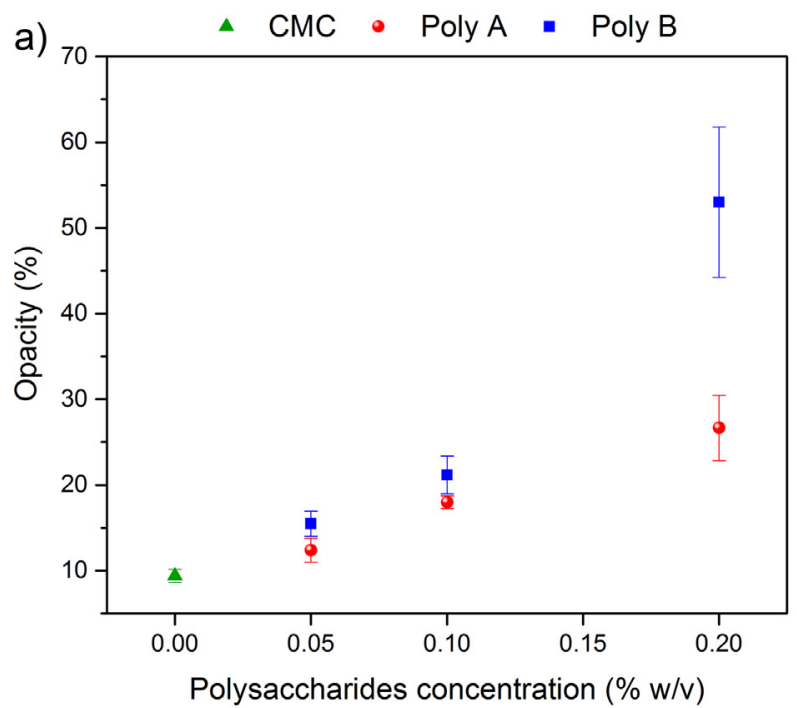

b)

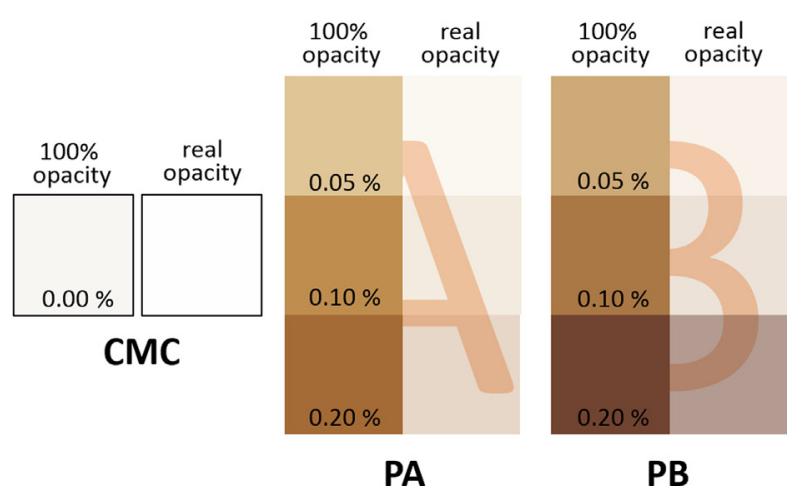

Fig. 6. Opacity values of films with increasing extract concentrations (a), evaluation of the film color when the opacity parameter is kept constant at $100 \%$ (left column) and when the real opacity is used to simulate the real color of the film (right column) (b).

films, except to PA 0.05\% (w/v) (data not shown), which is in agreement with the values reported for the film solubility. The reduction of contact angle is supported by the fact that the water was spread out through the film surface or adsorbed [31].

\subsection{Optical properties - color and opacity}

The results for color and opacity measurements are presented in Table 2. As can be seen, when PA or PB were incorporated into the film an evident change in color was noticed. The color of the film was changed from a very light transparent material (CMC film) to a brownish color, characteristic of the SCG samples. Moreover, films color was highly dependent of the amount of extract added to matrix, being observed a darker brown color when the concentration was increased. In general, the $a^{*}$ values of the films containing PA or PB suggested a trend to reddish, while $b^{*}$ values indicated a yellower appearance. $L^{*}$ values decreased when PA or PB concentrations were higher, while the opacity increased (Fig. 6a), being the highest value obtained for films with $0.20 \%(w / v)$ of PB. Although transparency is an appreciated feature in films since often it influences in the consumer choice, opacity is also an important attribute once films with this characteristic can be used to protect the food, acting as a barrier to light. The color and opacity simulation of the films is shown in Fig. 6b. In order to distinguish the film color, the opacity parameter was kept constant $(100 \%)$ in the left column of the graph considering only the $L^{*}, a^{*}$ and $b^{*}$ parameters, while the 
measured opacity was used in the right column to simulate the real color of the film. PA when used at different concentrations provided a film with less opaque color compared to PB. This is probably related to the amount of phenolic compounds and the interactions between they and polysaccharides present in the materials used in the production of the films [32]. Both, PA and PB samples contain phenolic compounds in mixture with polysaccharides [10,14]; however, PB was also subjected to Maillard reaction during autohydrolysis process, where it could have been generated additional pigments with influence in the opacity of the films.

\section{Conclusion}

This study demonstrated that the addition of SCG extracts rich in polysaccharides to the CMC-based film affected the film matrix and changed its properties, improving or at least preserving its physicochemical properties. Color and opacity were the main properties affected by the polysaccharideís incorporation, the light barrier of the film being significantly improved in the enriched films. In addition, since SCG polysaccharides present antioxidant and antimicrobial properties [10,14], their incorporation into the CMCbased film is able to provide important functional properties to the film, increasing even more the possibility of their application in the food area.

\section{Acknowledgements}

This work was supported by the Science and Technology Foundation of Portugal (FCT - grant SFRH/BD/80948/2011); the Strategic Project of UID/BIO/04469/2013 unit; and the Project BioInd - Biotechnology and Bioengineering for improved Industrial and Agro-Food processes (REF. NORTE-07-0124-FEDER-000028), Co-funded by the Programa Operacional Regional do Norte (ON.2-O Novo Norte), QREN, FEDER.

\section{References}

[1] B. Ghanbarzadeh, H. Almasi, A.A. Entezami, Physical properties of edible modified starch/carboxymethyl cellulose films, Innovative Food Sci. Emerg. Technol. 11 (2010) 697-702.

[2] J.T. Martins, M.A. Cerqueira, A.I. Bourbon, A.C. Pinheiro, B.W. Souza, A.A. Vicente, Synergistic effects between $\mathrm{K}$-carrageenan and locust bean gum on physicochemical properties of edible films made thereof, Food Hydrocolloids 29 (2012) 280-289.

[3] M.A. Cerqueira, A.M. Lima, J.A. Teixeira, R.A. Moreira, A.A. Vicente, Suitability of novel galactomannans as edible coatings for tropical fruits, J. Food Eng. 94 (2009) 372-378.

[4] S.I. Mussatto, E.M.S. Machado, S. Martins, J.A. Teixeira, Production: composition and application of coffee and its industrial residues, Food Bioprocess Technol. 4 (2011) 661-672.

[5] S.I. Mussatto, L.F. Ballesteros, S. Martins, J.A. Teixeira, Extraction of antioxidant phenolic compounds from spent coffee grounds, Sep. Purif. Technol. 83 (2011) 173-179.

[6] C. Conde, S.I. Mussatto, Isolation of polyphenols from spent coffee grounds and silverskin by mild hydrothermal pretreatment, Prep. Biochem. Biotechnol. 46 (2016) 406-409.

[7] S.I. Mussatto, L.M. Carneiro, J.P.A. Silva, I.C. Roberto, J.A. Teixeira, A study on chemical constituents and sugars extraction from spent coffee grounds, Carbohydr. Polym. 83 (2011) 368-374.

[8] S.I. Mussatto, Generating biomedical polyphenolic compounds from spent coffee or silverskin, in: V.R. Preedy (Ed.), Coffee in Health and Disease Prevention, Elsevier, London, UK, 2015, pp. 93-106.
[9] L.F. Ballesteros, J.A. Teixeira, S.I. Mussatto, Chemical functional, and structural properties of spent coffee grounds and coffee silverskin, Food Bioprocess Technol. 7 (2014) 3493-3503.

[10] L.F. Ballesteros, M.A. Cerqueira, J.A. Teixeira, S.I. Mussatto, Characterization of polysaccharides extracted from spent coffee grounds by alkali pretreatment, Carbohydr. Polym. 127 (2015) 347-354

[11] J. Simões, P. Madureira, F.M. Nunes, M.R. Domingues, M. Vilanova, M.A. Coimbra, Immunostimulatory properties of coffee mannans, Mol. Nutr. Food Res. 53 (2009) 1036-1043.

[12] J.-F. Su, Z. Huang, X.-Y. Yuan, X.-Y. Wang, M. Li, Structure and properties of carboxymethyl cellulose/soy protein isolate blend edible films crosslinked by Maillard reactions, Carbohydr. Polym. 79 (2010) 145-153.

[13] C. Bangyekan, D. Aht-Ong, K. Srikulkit, Preparation and properties evaluation of chitosan-coated cassava starch films, Carbohydr. Polym. 63 (2006) 61-71.

[14] L.F. Ballesteros, J.A. Teixeira, S.I. Mussatto, Extraction of polysaccharides by autohydrolysis of spent coffee grounds and evaluation of their antioxidant activity, Carbohydr. Polym. 157 (2017) 258-266.

[15] M.A. Cerqueira, B.W. Souza, J.A. Teixeira, A.A. Vicente, Effects of interactions between the constituents of chitosan-edible films on their physical properties, Food Bioprocess Technol. 5 (2012) 3181-3192.

[16] M. Gencturk, A. Bakshi, Y. Hong, T. Labuza, Moisture transfer properties of wild rice, J. Food Process Eng. 8 (1986) 243-261.

[17] A. Casariego, B. Souza, M. Cerqueira, J. Teixeira, L. Cruz, R. Díaz, A. Vicente, Chitosan/clay films' properties as affected by biopolymer and clay micro/nanoparticles' concentrations, Food Hydrocolloids 23 (2009) 1895-1902.

[18] M. Izydorczyk, J. Dexter, Barley $\beta$-glucans and arabinoxylans: molecular structure, physicochemical properties, and uses in food products-a review, Food Res. Int. 41 (2008) 850-868.

[19] M. Chai, M. Isa, The oleic acid composition effect on the carboxymethyl cellulose based biopolymer electrolyte, J. Cryst. Process Technol. 3 (2013) 1-4

[20] I. Yakimets, S.S. Paes, N. Wellner, A.C. Smith, R.H. Wilson, J.R. Mitchell, Effect of water content on the structural reorganization and elastic properties of biopolymer films: a comparative study, Biomacromolecules 8 (2007) $1710-1722$.

[21] M.A. Cerqueira, B.W. Souza, J.A. Teixeira, A.A. Vicente, Effect of glycerol and corn oil on physicochemical properties of polysaccharide films-a comparative study, Food Hydrocolloids 27 (2012) 175-184.

[22] M. Nanda, Z. Yuan, W. Oin, M. Poirier, X. Chunbao, Purification of crude glycerol using acidification: effects of acid types and product characterization, Austin J. Chem. Eng. 1 (2014) 1-7.

[23] S. Ebrahimzadeh, B. Ghanbarzadeh, H. Hamishehkar, Physical properties of carboxymethyl cellulose based nano-biocomposites with Graphene nano-platelets, Int. J. Biol. Macromol. 84 (2016) 16-23.

[24] M.S. Hoque, S. Benjakul, T. Prodpran, Properties of film from cuttlefish (Sepia pharaonis) skin gelatin incorporated with cinnamon: clove and star anise extracts, Food Hydrocolloids 25 (2011) 1085-1097.

[25] C. Mu, J. Guo, X. Li, W. Lin, D. Li, Preparation and properties of dialdehyde carboxymethyl cellulose crosslinked gelatin edible films, Food Hydrocolloids 27 (2012) 22-29.

[26] E. Arda, S. Kara, Ö. Pekcan, Synergistic effect of the locust bean gum on the thermal phase transitions of $\kappa$-carrageenan gels, Food Hydrocolloids 23 (2009) 451-459.

[27] V. Bifani, C. Ramírez, M. Ihl, M. Rubilar, A. García, N. Zaritzky, Effects of murta (Ugni molinae Turcz) extract on gas and water vapor permeability of carboxymethylcellulose-based edible films, LWT-Food Sci. Technol. 40 (2007) 1473-1481.

[28] S. Kim, Z. Ustunol, Solubility and moisture sorption isotherms of whey-protein-based edible films as influenced by lipid and plasticizer incorporation, J. Agric. Food Chem. 49 (2001) 4388-4391.

[29] E.A.A. Kibar, F. Us, Thermal, mechanical and water adsorption properties of corn starch-carboxymethylcellulose/methylcellulose biodegradable films, J. Food Eng. 114 (2013) 123-131.

[30] S. Inchuen, W. Narkrugsa, P. Pornchaloempong, Moisture sorption of Thai red curry powder, Maejo Int. J. Sci. Technol. 3 (2009) 486-497.

[31] T.D. Phan, F. Debeaufort, D. Luu, A. Voilley, Functional properties of edible agar-based and starch-based films for food quality preservation, J. Agric. Food Chem. 53 (2005) 973-981.

[32] J. Gómez-Estaca, B. Giménez, P. Montero, M. Gómez-Guillén, Incorporation of antioxidant borage extract into edible films based on sole skin gelatin or a commercial fish gelatin, J. Food Eng. 92 (2009) 78-85. 